\title{
Effect of Hypoxia on Myocardial Relaxation in Isometric Cat Papillary Muscle
}

\author{
William H. Frist, Igor Palacios, and Wm. John Powell, Jr., Department of \\ Medicine (Cardiac Unit) of the Massachusetts General Hospital and \\ Harvard Medical School, Boston, Massachusetts 02114
}

\begin{abstract}
A B S T RACT Myocardial relaxation is an important energy-dependent process. Hypoxia, unlike ischemia, has not been shown to impair myocardial relaxation. This difference may be because $(a)$ the traditional index to assess isometric muscle relaxation (half time to relaxation or $\mathrm{RT}_{1 / 2}$ ) reflects both changes in developed tension as well as relaxation and $(b)$ the relaxation process is highly sensitive to temperature and previous papillary muscle studies have been conducted under hypothermic conditions. The present study examines the effect of hypoxia on the relaxation process of 31 isometrically contracting kitten papillary muscles at hypothermic $\left(29^{\circ} \mathrm{C}\right)$ and euthermic $\left(38^{\circ} \mathrm{C}\right)$ conditions using $\mathrm{RT}_{1 / 2}$, the peak rate of tension fall $(-\mathrm{d} T / \mathrm{d} t)$ and $-\mathrm{d} T / \mathrm{d} t$ normalized for tension ([peak $-\mathrm{d} T / \mathrm{d} t] / T$ and max $[-\mathrm{d} T / \mathrm{d} t$ per $T])$. Hypoxia at $29^{\circ} \mathrm{C}$ resulted in a fall in $\mathrm{RT}_{1 / 2}$ from $278 \pm 11$ (SEM) to $230 \pm 17 \mathrm{~ms}(P$ $<0.01$ ) and no change in (peak $-\mathrm{d} T / \mathrm{d} t) / T$ and max $(-\mathrm{d} T / \mathrm{d} t$ per $T)$. However, at $38^{\circ} \mathrm{C}$, hypoxia impaired relaxation as reflected in a prolongation of $\mathrm{RT}_{1 / 2}$ from $101 \pm 6$ to $126 \pm 8 \mathrm{~ms}(P<0.01)$ in spite of a substantial fall in peak tension. Moreover, (peak $-\mathrm{d} T / \mathrm{d} t) / T$ decreased from $-15.4 \pm 0.7$ to $-11.0 \pm 0.8 / \mathrm{s} \quad(P<0.0 \mathrm{~d})$ and $\max (-\mathrm{d} T / \mathrm{d} t$ per $T)$ decreased from $-25.1 \pm 1.8$ to $-13.8 \pm 0.9 / \mathrm{s} \quad(P<0.01)$. In conclusion, the present study demonstrates that hypoxia impairs the relaxation process of cardiac muscle.
\end{abstract}

\section{INTRODUCTION}

In recent years myocardial relaxation, the process by which cardiac muscle returns to its initial length and tension after a contraction (1), has become recognized as an important phase of the cardiac cycle $(2,3)$. Relaxation has been shown to be a dynamic, energydependent process (4-6). Interventions which interfere with the energy supply to the heart muscle might therefore be expected to impair relaxation.

Received for publication 15 August 1977 and in revised form 21 November 1977.
Ischemia has recently been demonstrated under controlled hemodynamic conditions to prolong relaxation (7). To date, however, hypoxia, a major component of the ischemic state, has not been shown to impair the relaxation of cardiac muscle $(8-10)$.

Previous studies using the isometrically contracting papillary muscle preparation have reported a shortened time of relaxation associated with hypoxia $(8-10)$. This finding is most probably a function of two factors. First, alterations in the half time to relaxation $\left(\mathrm{RT}_{1 / 2}\right),{ }^{1}$ the index customarily applied to the evaluation of myocardial relaxation in isometric preparations, reflect changes in the magnitude of developed tension in addition to alterations in relaxation per se. Second, previous studies of hypoxia have been conducted under the conditions of hypothermia $(8-10)$. Because low temperatures have been shown to prolong myocardial relaxation $(11,12)$, the findings of the previous studies on hypoxia may be complicated by preexistent impairment of relaxation in the prehypoxic control period.

Therefore, the present study was undertaken to determine whether acute hypoxia impairs myocardial relaxation using the isometrically contracting kitten papillary muscle preparation. Data were collected at temperatures which are physiologic for the kitten, and the results were compared with those obtained under hypothermic conditions.

\section{METHODS}

Right ventricular papillary muscles (cross-sectional area $=0.64 \pm 0.05 \mathrm{~mm}^{2}$ ) were obtained from 31 kittens after being anesthetized by the intraperitoneal injection of sodium pentobarbital (30 mg/kg). The muscle was rapidly removed and suspended in a $20-\mathrm{ml}$ bath containing a modified KrebsRinger solution: $143 \mathrm{mM}$ sodium, $4.1 \mathrm{mM}$ potassium, $2.5 \mathrm{mM}$ calcium, $1.3 \mathrm{mM}$ magnesium, $1.3 \mathrm{mM}$ phosphate, $126 \mathrm{mM}$ chloride, $25 \mathrm{mM}$ bicarbonate, and $5.5 \mathrm{mM}$ glucose. Fresh

${ }^{1}$ Abbreviation used in this paper: $\mathrm{RT}_{1 / 2}$, half time to relaxation. 
solution flowed by gravity through the bath at a rate of 5 $\mathrm{ml} / \mathrm{min}$ from reservoir bottles situated about the bath. The reservoir and muscle bath were bubbled with a gas mixture of $95 \% \quad \mathrm{O}_{2} / 5 \% \mathrm{CO}_{2}$. Bath temperature was maintained at either $29^{\circ} \mathrm{C}(n=18)$ or $38^{\circ} \mathrm{C}(n=13)$ for each muscle, using a Lauda model K2-D (Messgerate Werk Lauda Co., West Germany) temperature-controlled circulating pump. The bath temperature was continuously monitored using a model 43-TD temperature unit (Yellow Springs Instrument Co., Yellow Springs, Ohio) and KM-5103 temperature probe (King Engineering Corp., Ann Arbor, Mich.).

Both ends of the muscle were attached to spring-loaded Lucite clips (Massachusetts General Hospital, Medical Engineering Department). The tendinous end was held by the upper clip, which was connected via a steel rod to a Sanborn FTA-10 (Hewlett Packard Co., Lexington Mass.) force transducer. The base of the muscle was attached by the lower clip, which was secured to a rigid Palmer stand by a steel pin that penetrated the bottom of the bath. The displacement of the transducer and clips was $<0.05 \mathrm{~mm} / 10 \mathrm{~g}$ tension. All studies were performed under isometric conditions. The muscle was paced using an SD9 stimulator (Grass Instrument Co., Quincy, Mass.) at a rate of $12 \mathrm{stimuli} / \mathrm{min}$ through platinum electrodes placed parallel to the longitudinal axis of the muscle delivering DC impulses of a 4-ms duration at a voltage of $20 \%$ above threshold.

After an hour of stabilization, during which each muscle was electrically stimulated and maintained at $0.7-1.0 \mathrm{~g}$ of resting tension, the length at which resting tension was just perceptibly greater than zero was determined. The muscle was then gradually adjusted to a total length of $120 \%$ of this zero resting-tension length. After an additional 30-45 min of stabilization, prehypoxic control readings were recorded every $3 \mathrm{~min}$ for at least $15 \mathrm{~min}$.

Hypoxia was produced for either 15 - or $30-$ min periods by rapidly switching from the control solution bubbled with $95 \% \mathrm{O}_{2} / 5 \% \mathrm{CO}_{2}$ to a solution actively bubbled with $95 \%$ $\mathrm{N}_{2} / 5 \% \mathrm{CO}_{2}$. The $\mathrm{pH}$ and $\mathrm{PCO}_{2}$ were maintained nearly constant throughout each experiment. Determinations of $\mathrm{pH}$, $\mathrm{PCO}_{2}$ and $\mathrm{PO}_{2}$ were made using a Radiometer PHM 72 (Radiometer Copenhagen Co., Copenhagen, Denmark) digital acid-base analyzer. After the hypoxic period, the muscle was reoxygenated with $95 \% \quad \mathrm{O}_{2} / 5 \% \quad \mathrm{CO}_{2}$, and data were collected for an additional $15 \mathrm{~min}$. At the conclusion of each experiment, the muscle was removed from the chamber, gently blotted on filter paper, and weighed. The cross-sectional area was calculated from the weight and length of the muscle by assuming cylindrical uniformity and a specific gravity of 1.000 .

High and low sensitivity recordings of tension, the first derivative of tension, the first derivative of tension divided by instantaneous tension, and the stimulus artifact were simultaneously recorded at 3-min intervals at a paper speed of $100 \mathrm{~mm} / \mathrm{s}$ on a six-channel Sanborn model 7700 recorder. The first derivative of tension $(\mathrm{d} T / \mathrm{d} t)$ was obtained by electronic differentiation of the output channel of the tension recording and calibrated by supplying a wave form of known slope to the differentiating circuit, which has a time constant of $0.001 \mathrm{~s}$ and a cutoff at 160 cycles/s. The first derivative of tension divided by instantaneous tension was obtained by continuous analogue division. To accomplish this, a tension signal processor was specifically designed to convert an input signal $T(t)+V$ (developed tension) into an output signal $K \times(\mathrm{d} T[t] / \mathrm{d} t / T[t])$ by electronically differentiating the logarithm of tension.

In analyzing the data, the following measurements were made: $(a)$ peak tension, or the maximum developed tension after stimulation, normalized for cross-sectional area, in grams per square millimeter; $(b)$ the time to peak tension, or the time from the stimulus artifact to the time of peak tension, in milliseconds; (c) $\mathrm{RT}_{1 / 2}$, or the time for tension to fall from peak tension to half peak tension, in milliseconds; $(d)$ 95\% relaxation time $\left(\mathrm{RT}_{95 \%}\right)$, or the time for tension to fall from peak tension to $5 \%$ of peak developed tension, in milliseconds; $(e)$ peak rate of tension development (peak $+\mathrm{dT} / \mathrm{dt}$ ), or the maximum of the first derivative of tension, in grams per second per square millimeter; $(f)$ peak rate of tension decline (peak $-\mathrm{d} T / \mathrm{d} t$ ), or the minimum of the first derivative of tension, in grams per second per square millimeter; $(g$ ) peak rate of tension decline divided by the instantaneous tension at which peak $-\mathrm{d} T / \mathrm{d} t$ occurred ([peak $-\mathrm{d} T / \mathrm{d} t] / T)$, measured per second; (h) maximum value of the quotient obtained by the continuous division of the rate of tension decline by instantaneous tension $(\max [-\mathrm{d} T / \mathrm{d} t$ per $T])$, measured per second.

The data were analyzed statistically by the double-tailed Student's $t$ test and differences considered significant at the level of $P \leq 0.05$. All values preceded by \pm represent plus or minus SEM.

\section{RESULTS}

Data were obtained from 13 papillary muscles under euthermic conditions $\left(38^{\circ} \mathrm{C}\right)$ and from 18 muscles under hypothermic conditions $\left(29^{\circ} \mathrm{C}\right)$. Table I shows that cross-sectional area and preload were comparable for both groups of muscles. Preload did not change significantly throughout each experiment. A similar hypoxic stress was applied to both groups of muscles by rapidly replacing the well-oxygenated control solution with solution equilibrated with $95 \% \mathrm{~N}_{2} / 5 \% \mathrm{CO}_{2}$. For the euthermic muscles, the mean control oxygen tension was $483 \pm 24 \mathrm{~mm} \mathrm{Hg}$, which fell abruptly to $70 \pm 4 \mathrm{~mm} \mathrm{Hg}$ within $3 \mathrm{~min}$ of the onset of hypoxia. For the hypothermic group, the control $\mathrm{PO}_{2}$ was 499 $\pm 16 \mathrm{~mm} \mathrm{Hg}$, which decreased to $68 \pm 3 \mathrm{~mm} \mathrm{Hg}$ at 3 min. The $\mathrm{pH}$ and $\mathrm{PCO}_{2}$ were similar at both tempera-

TABLE I

Data from the Hypothermic and Euthermic Papillary Muscles

\begin{tabular}{|c|c|c|}
\hline & $29^{\circ} \mathrm{C}$ & $38^{\circ} \mathrm{C}$ \\
\hline Number of muscles & 18 & 13 \\
\hline Cross-sectional area, $\mathrm{mm}^{2}$ & $0.61 \pm 0.07$ & $0.68 \pm 0.05$ \\
\hline Preload, $g$ & $0.79 \pm 0.04$ & $0.77 \pm 0.08$ \\
\hline $\mathrm{pH}$ & $7.43 \pm 0.02$ & $7.43 \pm 0.02$ \\
\hline$P_{\mathrm{CO}_{2}}, m m H g$ & $36 \pm 1$ & $34 \pm 2$ \\
\hline \multicolumn{3}{|l|}{ Time to peak tension, $m s$} \\
\hline Control & $470 \pm 17$ & $236 \pm 8$ \\
\hline Hypoxia, $30 \mathrm{~min}$ & $386 \pm 21 *$ & $182 \pm 7^{*}$ \\
\hline Reoxygenation, $15 \mathrm{~min}$ & $559 \pm 46$ & $252 \pm 19 \ddagger$ \\
\hline \multicolumn{3}{|l|}{$\mathrm{RT}_{95 \%}, m s$} \\
\hline Control & $515 \pm 22$ & $200 \pm 11$ \\
\hline Hypoxia, $30 \mathrm{~min}$ & $487 \pm 65^{*}$ & $232 \pm 14 \ddagger$ \\
\hline Reoxygenation, $15 \mathrm{~min}$ & $796 \pm 86^{*}$ & $254 \pm 18 \ddagger$ \\
\hline
\end{tabular}

$* P<0.01$.

$\ddagger P<0.05$. 
CONTROL
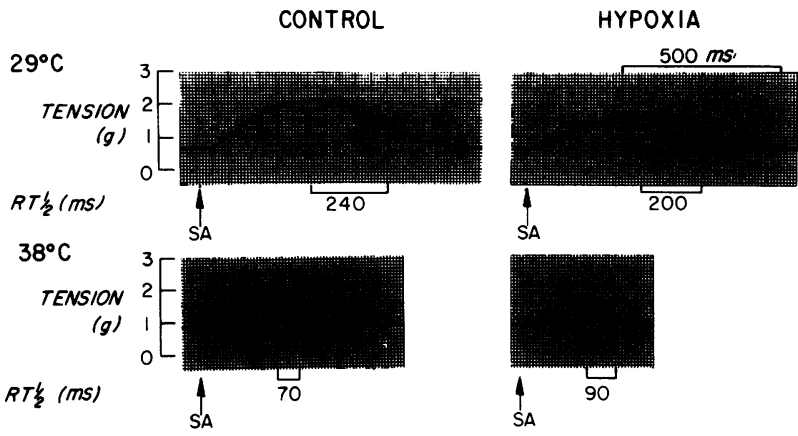

FIGURE l Isometric contractions under well-oxygenated control conditions (left panels) and during $15 \mathrm{~min}$ of hypoxia (right panels) at both $29^{\circ} \mathrm{C}$ (top) and $38^{\circ} \mathrm{C}$ (bottom). $\mathrm{SA}=$ stimulus artifact.

tures (Table I) and did not change significantly between control and hypoxic conditions.

Representative single-twitch recordings of tension under well-oxygenated and hypoxic conditions at both $29^{\circ}$ and $38^{\circ} \mathrm{C}$ are shown in Fig. 1. The mean results of peak tension and maximum rate of tension development for both temperatures are shown in Fig. 2 and the upper panel of Fig. 3, and the results of time to

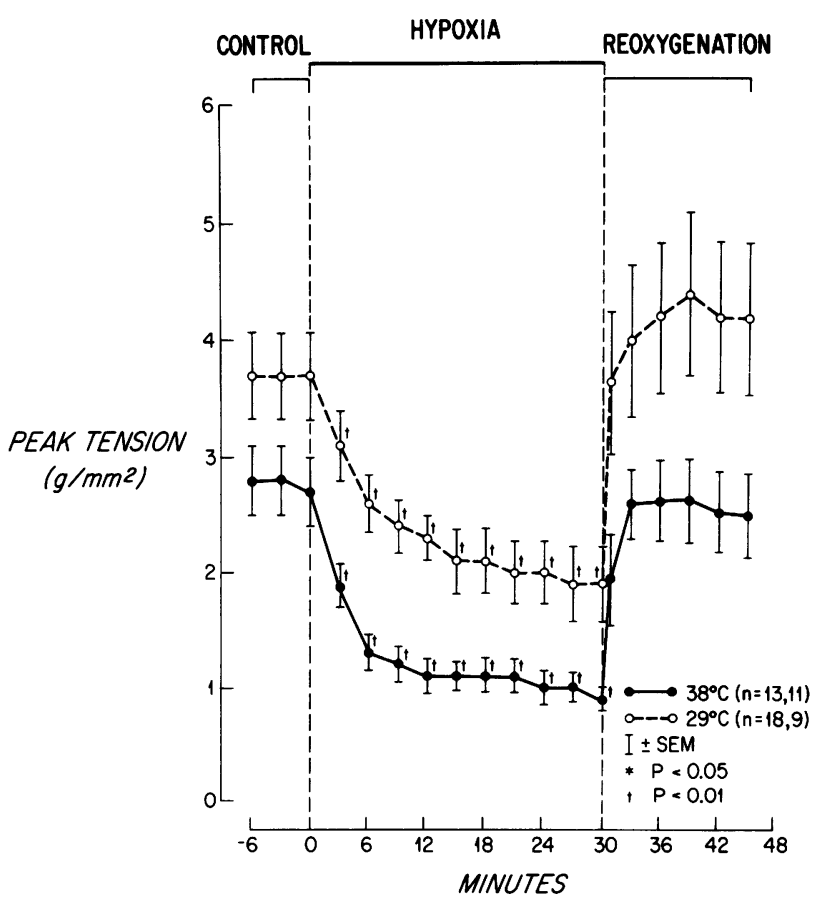

FIGURE 2 Changes in the peak tension of euthermic and hypothermic papillary muscles produced by hypoxia of $30 \mathrm{~min}$ duration followed by $15 \mathrm{~min}$ of reoxygenation. Note that the magnitude of tension decrease produced under the two conditions was similar. $n=13,11$ : Hypoxia was produced for 15 min in all muscles and continued for $30 \mathrm{~min}$ in 11 of the 13 . $n=18,9$ : Hypoxia was produced for $15 \mathrm{~min}$ in all 18 muscles and continued for $30 \mathrm{~min}$ in 9 of the 18 .

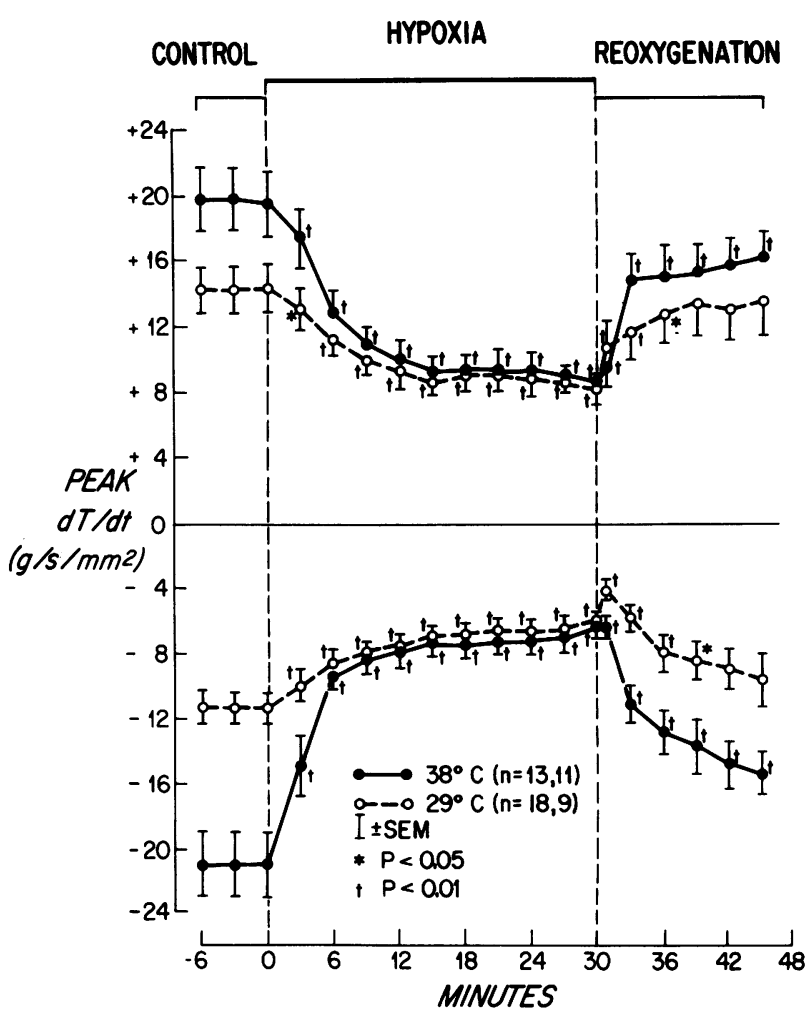

FIGURE 3 Changes in the peak $+\mathrm{d} T / \mathrm{d} t$ (upper panel) and in the peak $-\mathrm{d} T / \mathrm{d} t$ (lower panel) of euthermic and hypothermic papillary muscles produced by hypoxia of $30 \mathrm{~min}$ duration followed by $15 \mathrm{~min}$ of reoxygenation. Numbers of experiments as in legend of Fig. 2.

peak tension are shown in Table I. In well-oxygenated control conditions, before the onset of hypoxia, the euthermic muscles are characterized by a smaller peak developed tension (Fig. 2), a shorter time to peak tension (Table I), and faster rate of tension development (upper panel of Fig. 3).

In response to hypoxia, peak tension (Fig. 2) fell by approximately the same absolute amount at both temperatures $\left(1.85 \mathrm{~g} / \mathrm{mm}^{2}\right.$ at $38^{\circ} \mathrm{C}$ and $1.82 \mathrm{~g} / \mathrm{mm}^{2}$ at $\left.29^{\circ} \mathrm{C}\right)$. The effect of hypoxia on time to peak tension and peak $+\mathrm{d} T / \mathrm{d} t$ are shown in Table I and Fig. 3 . At $38^{\circ} \mathrm{C}$, time to peak tension fell $18 \%$ from a prehypoxic level of $236 \pm 8$ $\mathrm{ms}$, and at $29^{\circ} \mathrm{C}$ it fell $15 \%$ from a control of $470 \pm 17 \mathrm{~ms}$. The upper panel of Fig. 3 shows that peak $+\mathrm{d} T / \mathrm{d} t$ for both groups of muscles decreased to the same level soon after the onset of hypoxia, although the absolute fall for the euthermic group was greater than that for the hypothermic group. These changes in contractile performance are all consistent with a negative inotropic effect of hypoxia. During early reoxygenation, peak tension, time to peak tension, and peak $+\mathrm{d} T / \mathrm{d} t$ rapidly recovered to prehypoxic values (Fig. 2, Table I, and the upper panel of Fig. 3). 
The mean values for indices that characterize relaxation are displayed in the lower panel of Fig. 3, Figs. 4 and 5 , and Table I. The $\mathrm{RT}_{1 / 2}$ values associated with a single twitch are given in Fig. 1. In the well-oxygenated control state, the hypothermic group relaxed more slowly than the euthermic group, as evidenced by the control $\mathrm{RT}_{1 / 2}$ of $278 \pm 11 \mathrm{~ms}$ for $29^{\circ} \mathrm{C}$ and $101 \pm 6 \mathrm{~ms}$ for $38^{\circ} \mathrm{C}$ (Fig. 4). The other measures of relaxation (lower panel of Fig. 3, Figs. 4 and 5, and Table I) similarly reflect relative impairment of relaxation in the prehypoxic, well-oxygenated state of the hypothermic muscles when compared to euthermic muscles.

In the hypothermic studies, hypoxia was associated with a decrease in relaxation time with $\mathrm{RT}_{1 / 2}$ (Fig. 4) falling from $278 \pm 11$ to $230 \pm 17 \mathrm{~ms}$. This shortening of $\mathrm{RT}_{1 / 2}$ during hypoxia is in agreement with previous studies $(8-10)$. When the same external hypoxic stress is applied to muscles under conditions of euthermia, the indices of relaxation indicate a strikingly dissimilar response. Under this more physiologic temperature, $\mathrm{RT}_{1 / 2}$ increased rapidly from a control of $101 \pm 6$ to $126 \pm 8 \mathrm{~ms}$ at 6 min after the onset of hypoxia. $\mathrm{RT}_{1 / 2}$ remained significantly prolonged compared with control values for

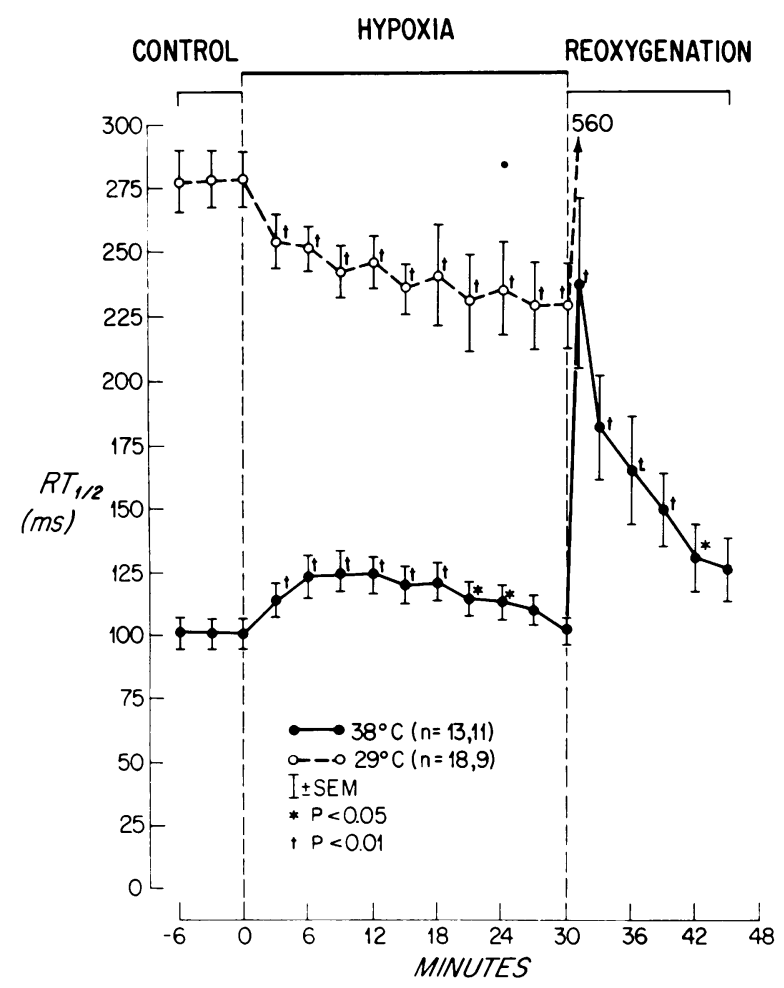

FIGURE 4 Changes in the half time to relaxation of euthermic and hypothermic muscles produced by hypoxia of $30 \mathrm{~min}$ duration followed by 15 min of reoxygenation. Note that with hypoxia the half time to relaxation shortens under hypothermic conditions $(O)$ but lengthens under euthermic conditions (๑). Numbers of experiments as in legend of Figure 2.

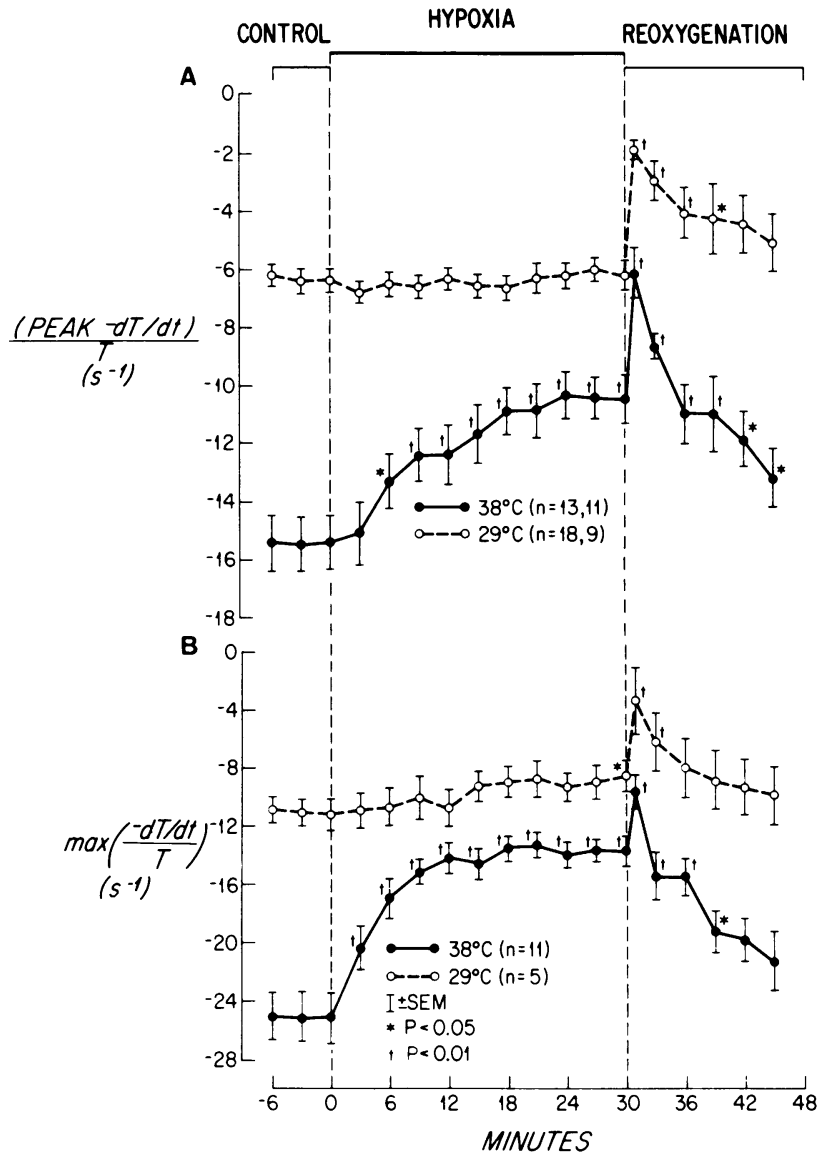

FIGURE 5 (A) Changes produced by hypoxia in peak $-\mathrm{d} T /$ $\mathrm{d} t$ divided by the instantaneous tension at which peak $-\mathrm{d} T /$ $\mathrm{d} t$ occurred. The data are from euthermic and hypothermic papillary muscles. Abbreviation: (peak $-\mathrm{d} T / \mathrm{d} t) / T=$ peak $-\mathrm{d} T / \mathrm{d} t$ divided by the instantaneous tension at which peak $-\mathrm{d} T / \mathrm{d} t$ occurred. Numbers of experiments as in legend of Figure 2. (B) Changes produced by hypoxia in the maximum value of the quotient obtained by the continuous division of the rate of tension decline by instantaneous tension, max $(-\mathrm{d} T / \mathrm{d} t$ per $T)$, from euthermic and hypothermic papillary muscles.

the first 24 min of hypoxic exposure. The tendency for $\mathrm{RT}_{1 / 2}$ to shorten gradually during the last half of hypoxia may, in part, be attributable to the associated slight decrease in peak tension and time to peak tension.

Data from another measure of the duration of relaxation, $\mathrm{RT}_{95}$, are given in Table $\mathrm{I}$. $\mathrm{RT}_{95 \%}$ was determined in order to approximate total relaxation time. For the euthermic muscles, the index increased from a control of $200 \pm 11$ to $255 \pm 16 \mathrm{~ms}$ at $6 \mathrm{~min}$ after the onset of hypoxia and remained significantly prolonged throughout the entire period of hypoxia.

Under euthermic conditions, the absolute value for peak $-\mathrm{d} T / \mathrm{d} t$ (lower panel of Fig. 3) fell substantially during the first $6 \mathrm{~min}$ of hypoxia, from $-21.0 \pm 2.0$ to 
$-8.4 \pm 0.9 \mathrm{~g} / \mathrm{s}$ per $\mathrm{mm}^{2}$, after which it tended to plateau and followed a course similar to that of the hypothermic muscles. The upper panel of Fig. 5 displays an adjusted index which was obtained by dividing peak $-\mathrm{d} T / \mathrm{d} t$ by the instantaneous absolute isometric tension at which it occurs ([peak $-\mathrm{d} T / \mathrm{d} t] / T)$. This index represents an attempt to normalize the rate of tension fall for the inotropic effects of hypoxia on tension and thereby permit a more direct examination of relaxation. Consistent with the $\mathrm{RT}_{1 / 2}$ data for the euthermic muscles, these results also suggest impairment of relaxation during hypoxia. The absolute magnitude of (peak $-\mathrm{d} T /$ $\mathrm{d} t) / T$ fell throughout hypoxia from a control value of $-15.4 \pm 0.7$ to $-11.0 \pm 0.8 / \mathrm{s}$ at the end of hypoxia (upper panel of Fig. 5). In addition, the absolute magnitude of $\max (-\mathrm{d} T / \mathrm{d} t$ per $T)$, another index normalized for tension, fell from $-25.1 \pm 1.8$ to $-13.8 \pm 0.9 / \mathrm{s}$ during hypoxia, decreasing rapidly during the initial half of the hypoxic period and more slowly thereafter (lower panel of Fig. 5 ). These considerable changes in normalized indices of relaxation at $38^{\circ} \mathrm{C}$ contrast with the apparent lack of effect that hypoxia has on relaxation at $29^{\circ} \mathrm{C}$. Under conditions of hypothermia, hypoxia did not alter (peak $-\mathrm{d} T / \mathrm{d} t) / T$. Moreover, $\max (-\mathrm{d} T / \mathrm{d} t$ per $T)$ did not change significantly from the preintervention values except at a single reading at $30 \mathrm{~min}$ of hypoxia.

During early reoxygenation, relaxation indices at $38^{\circ}$ and $29^{\circ} \mathrm{C}$ reflected dramatic impairment with the single exception of peak $-\mathrm{d} T / \mathrm{d} t$ at $38^{\circ} \mathrm{C}$. These indices at both temperatures improved after the initial minute, and recovery continued toward control values throughout the remainder of reoxygenation.

\section{DISCUSSION}

The results of the present study clearly demonstrate that acute hypoxia impairs myocardial relaxation under euthermic conditions in the isometrically contracting kitten papillary muscle. This impairment is reflected by significant changes in all the indices of relaxation applied in the present study. With the onset of hypoxia under euthermic conditions, relaxation is abruptly impaired and near maximally prolonged early in the hypoxic course during the time in which peak tension undergoes its most rapid fall. The effect of hypoxia on relaxation appears reversible, as suggested by the return toward control values of the relaxation indices during reoxygenation.

During hypoxia, the $\mathrm{RT}_{1 / 2}$ of the euthermic muscles becomes substantially prolonged in the presence of decreasing developed tension. This increase in duration of relaxation contrasts with the hypothermic data from this study and with the results of previous studies also carried out under hypothermic conditions (8-10). Data obtained during hypothermic demonstrate shortening of the relaxation time during hypoxia. This dis- crepancy between the euthermic and the hypothermic data may be explained by the factors which influence the traditionally employed index $\mathrm{RT}_{1 / 2}$ and by the low temperatures under which previous studies of hypoxia have been performed.

Largely because the course of tension fall in the isometric myocardial preparation cannot be described by a single exponential time constant (11), previous studies have relied primarily on a measure of the duration of relaxation. The index $\mathrm{RT}_{1 / 2}$, because of the ease and precision with which it can be measured (2), has been most often used. $\mathrm{RT}_{1 / 2}$ is defined as the time for tension to decline from its peak to half peak value. The principal determinants of this index are the magnitude of developed tension and the rate at which tension declines from peak tension until the time at which half peak tension occurs. Hypoxia, therefore, would be expected to produce changes in $\mathrm{RT}_{1 / 2}$ through two counteracting forces: $(a)$ the fall of peak tension, which at a constant rate of tension decline would tend to shorten the duration of $\mathrm{RT}_{1 / 2}$, and $(b)$ the decrease in the rate of tension decline, which if peak tension were to remain unchanged would tend to prolong $\mathrm{RT}_{1 / 2}$.

$\mathrm{RT}_{1 / 2}$ is prolonged during hypoxia under normothermic conditions because the rate of tension decline more than offsets the shortening effect of the simultaneous fall in peak tension. Under hypothermia, however, the abbreviating effect on $\mathrm{RT}_{1 / 2}$ by the fall in peak tension predominates; the net effect is a shortening of $\mathrm{RT}_{1 / 2}$. Thus, the fundamental limitation of $\mathrm{RT}_{1 / 2}$ as an index of relaxation with hypoxia rests with its dependence on peak developed tension. An example of this dependence on tension may be the downward shift of $\mathrm{RT}_{1 / 2}$ that occurs throughout hypoxia in the hypothermic papillary muscle and during late hypoxia in the euthermic muscle (Fig. 4). In spite of the limitations of measurements of duration as indices of relaxation, both the $\mathrm{RT}_{1 / 2}$ and the $\mathrm{RT}_{95 \%}$ data in the present study demonstrate that at physiologic temperatures hypoxia impairs myocardial relaxation.

To characterize more fully the effects of hypoxia on relaxation, indices that reflect the rate at which tension declines were examined. In the whole heart, peak $-\mathrm{d} P / \mathrm{d} t$, the maximal rate of pressure decline after end ejection, has been applied as an index of myocardial relaxation (13-15), but its magnitude has been shown to be influenced by developed pressure (14). Similarly, a recent study using isolated papillary muscle applied peak $-\mathrm{d} T / \mathrm{d} t$ to characterize isometric relaxation and demonstrated that peak $-\mathrm{d} T / \mathrm{d} t$ is influenced by developed tension (16). In an attempt to normalize peak $-\mathrm{d} T / \mathrm{d} t$ for the change in tension produced by hypoxia, two additional indices of relaxation were examined: peak $-\mathrm{d} T / \mathrm{d} t$ divided by the instantaneous tension at which peak $-\mathrm{d} T / \mathrm{d} t$ occurred, and the maximum value of the continuous division of the rate of tension fall 
$(-\mathrm{d} T / \mathrm{d} t)$ by the corresponding instantaneous tension. Data obtained using these two indices were consistent with impairment of relaxation during hypoxia under conditions of euthermia. Under hypothermic conditions, the hypoxia insult did not substantially alter the prehypoxic control values.

Although it is clear from the present study that hypoxia prolongs relaxation at $38^{\circ} \mathrm{C}$, the detailed mechanism underlying this depression remains to be defined. Intracellular calcium dynamics govern the contraction-relaxation cycle of cardiac muscle. Electrical excitation of the cell surface membrane releases calcium from intracellular storage compartments, particularly the sarcoplasmic reticulum. As the myofibrillar calcium concentration increases from $0.01-10.0 \mu \mathrm{M}$ under well-oxygenated conditions (17), calcium binds to troponin, thereby releasing the troponin-tropomyosin inhibition of the interaction of actin with heavy meromyosin, and contractile sites are activated. Tension and rate of tension development reflect the number of sites activated, which in turn relate directly to the quantity of calcium released upon excitation (18, 19). The active sequestration of the released calcium into the sarcoplasmic reticulum and to a minor extent other subcellular compartments regulates relaxation in mammalian cardiac muscle. When the calcium in the region of the myofilaments is reduced to a concentration no longer adequate to prevent inhibition of actinmyosin bridge formation, relaxation occurs. Reuptake of calcium is thought to proceed in two stages: an initial binding to the sarcoplasmic reticulum membrane, and subsequent slower transport across the vesicular wall $(20,21)$. The rate of transport is determined by the activation of a membrane ATPase, which in turn is influenced by the calcium concentration (22) and by the availability of ATP.

The impairment of relaxation observed with hypoxia may be a consequence of reduced removal of calcium from troponin. The underlying mechanism may be a reduction of a pool of ATP, possibly compartmentalized and small, that is vital for the enzymatic uptake of calcium by the sarcoplasmic reticulum. Indeed, some observers have found substantial reductions in the high energy phosphate stores in hypoxic hearts (23). Since calcium sequestration by the sarcoplasmic reticulum has been shown to be ATP-dependent (17), reduced energy supplies would diminish this process. Increased concentrations of calcium remaining in the myofibrillar region, by whatever mechanism, would cause binding of calcium with troponin, permit continued cross-bridge formation, and therefore impair relaxation.

The question of why the same low level of oxygen tension impairs relaxation at $38^{\circ} \mathrm{C}$ and does not appear to do so at $29^{\circ} \mathrm{C}$ cannot be answered with certainty from the present study. It is evident from the present data that in the control state before exposure to hypoxia, relaxation of the hypothermic muscle is substantially prolonged when compared to that of the euthermic muscle. Low temperature alone may have so severely slowed the enzymatic removal of calcium from the myofibrillar region that there is very limited potential for the subsequent hypoxic insult to depress further the uptake of calcium into the sarcoplasmic reticulum. This is consistent with in vitro findings that low temperatures slow calcium uptake by sarcoplasmic reticulum prepared from cardiac muscle (24) and skeletal muscle $(25,26)$. Additionally, as yet undefined mechanisms at low temperatures may impair relaxation by overloading the relaxation system with an increased intracellular concentration of calcium $(27,28)$. In contrast, at normal cardiac temperature, the depressive influences of low temperatures on relaxation are avoided and the impairment of relaxation by the hypoxic insult becomes apparent. This study should not imply that all papillary muscle studies be conducted at $38^{\circ} \mathrm{C}$. Selection of thermal conditions for a given set of experiments should be determined by the particular physiologic mechanisms under study.

This study was conducted using isometric conditions. Relaxation occurs at the same external fiber length that exists at the end of contraction. Similarly, in the intact heart, the fall in isovolumic pressure occurs at the end-systolic volume. Under isometric conditions, however, external muscle shortening does not occur during contraction, although minimal internal shortening of the contractile element does occur. Thus, in the isometric model, shortening deactivation of contraction is minimized, and it is possible that persistent mechanical activity may interfere with relaxation. However, in the present study, the limitations inherent in the isometric model would be expected to apply to the control conditions of oxygenation and to hypoxia at hypothermia and euthermia. Thus, the observed response of impairment of relaxation at $38^{\circ} \mathrm{C}$ may be attributed solely to the intervention of hypoxia.

At the temperatures applied in this investigation, a central core of relative hypoxia may exist. There is little consensus among the numerous studies debating the critical diameters of muscles for adequate oxygenation (29-33). Irrespective of whether a central core of hypoxia existed in the present study, the application of a severe hypoxic insult at normal cardiac temperatures clearly resulted in impairment of myocardial relaxation.

\section{ACKNOWLEDGMENTS}

The authors wish to thank Mr. Luis Guerrero and Miss Mary McGovern for their technical assistance and Miss Lois Sturm for her secretarial assistance.

Supported in part by U. S. Public Health Service grants 5P50 HL 17665, National Heart and Lung Institute grant HL 
07028, and HL 06664. Dr. Palacios was supported by a grant from the Universidad Central de Venezuela.

\section{REFERENCES}

1. Hill, A. V. 1949. The energetics of relaxation in the muscle twitch. Proc. R. Soc. Lond. B Biol. Sci. 136: 211-219.

2. Weisfeldt, M. L., P. W. Armstrong, H. E. Scully, C. A. Sanders, and W. M. Daggett. 1974. Incomplete relaxation between beats after myocardial hypoxia and ischemia. $J$. Clin. Invest. 53: 1626-1636.

3. Grossman, W., and L. P. McLaurin. 1976. Diastolic properties of the left ventricle. Ann. Intern. Med. 84: 316-326.

4. Fanburg, B., R. M. Finkel, and A. Martonosi. 1964. The role of calcium in the mechanism of relaxation of cardiac muscle. J. Biol. Chem. 239: 2298-2306.

5. Katz, A. M., and D. I. Repke. 1973. Calcium-membrane interactions in the myocardium: effects of ouabain, epinephrine, and $3^{\prime}, 5^{\prime}$-cyclic adenosine monophosphate. Am. J. Cardiol. 31: 193-201.

6. Langer, G. A. 1968. Ion fluxes in cardiac excitation and contraction and their relation to myocardial contractility. Physiol. Rev. 48: 708-757.

7. Palacios, I., and W. J. Powell, Jr. 1977. Effect of acute global ischemia on diastolic relaxation in canine hearts. Am. J. Cardiol. 39: 282. (Abstr.)

8. Tyberg, J. V., L. A. Yeatman, W. W. Parmley, C. W. Urschel, and E. H. Sonnenblick. 1970. Effects of hypoxia on mechanics of cardiac contraction. Am. J. Physiol. 218: 1780-1788.

9. Nakhjavan, F. K., R. Parameswaran, C. Y. Lu, N. V. Srinivasan, and H. Goldberg. 1971. Effects of hypoxia, reoxygenation, and temperature on cat papillary muscle. Am. J. Physiol. 220: 1289-1293.

10. Bing, O. H., J. F. Keefe, M. J. Wolk, L. J. Finkelstein, and $H$. Levine. 1971. Tension prolongation during recovery from myocardial hypoxia. J. Clin. Invest. 50: 660-666.

11. Parmley, W. W., and E. H. Sonnenblick. 1969. Relation between mechanics of contraction and relaxation in mammalian cardiac muscle. Am. J. Physiol. 216: 1084-1091.

12. Mattiazzi, A. R., and E. Nilsson. 1975. The influence of temperature on the time course of the mechanical activity in rabbit papillary muscle. Acta Physiol. Scand. 97: 310318.

13. Cohn, P. F., A. J. Liedtke, J. Serur, E. H. Sonnenblick, and C. W. Urschel. 1972. Maximal rate of pressure fall (peak negative $\mathrm{dP} / \mathrm{dt}$ ) during ventricular relaxation. Cardiovasc. Res. 6: 263-267.

14. Weisfeldt, M. L., H. E. Scully, J. Frederiksen, J. J. Rubenstein, G. M. Pohost, E. Beierholm, A. G. Bello, and W. M. Daggett. 1974. Hemodynamic determinants of maximum negative $\mathrm{dP} / \mathrm{dt}$ and periods of diastole. Am. J. Physiol. 227: 613-621.

15. McLaurin, L. P., E. L. Rolett, and W. Grossman. 1973. Impaired left ventricular relaxation during pacing induced ischemia. Am. J. Cardiol. 32: 751-757.

16. Tamiya, K., S. Kikkawa, A. Gunji, M. Hori, and Y. Sakurai. 1977. Maximum rate of tension fall during isometric relaxation at end-systolic fiber length in canine papillary muscle. Circ. Res. 40: 584-589.
17. Hellam, D. C., and R. J. Podolsky. 1969. Force measurements in skinned muscle fibres. J. Physiol. (Lond.). 200: $807-819$.

18. Morad, M., and Y. Goldman. 1973. Excitation-contraction coupling in heart muscle: membrane control of development of tension. Prog. Biophys. Mol. Biol. 27: 257-313.

19. New, W., and W. Trautwein. 1972. The ionic nature of slow inward current and its relation to contraction. Pflugers Arch. Eur. J. Physiol. 334: 24-38.

20. Ohnishi, T., and S. Ebashi. 1964. The velocity of calcium binding of isolated sarcoplasmic reticulum. J. Biochem. (Tokyo). 55: 599-603.

21. Ebashi, S. 1965. Sarcoplasmic reticulum and excitation contraction coupling. In Molecular Biology of Muscular Contraction. S. Ebashi, F. Oosawa, T. Sekine, and Y. Tonomura, editors. Elsevier Scientific Publishing Co., Amsterdam. 197.

22. Weber, A., R. Herz, and I. Reiss. 1963. On the mechanism of the relaxing effect of fragmented sarcoplasmic reticulum. J. Gen. Physiol. 46: 679-702.

23. Dhalla, N. S., J. C. Yates, D. A. Walz, V. A. McDonald, and R. E. Olson. 1972. Correlation between changes in the endogenous energy stores and myocardial function due to hypoxia in the isolated perfused rat heart. Can. J. Physiol. Pharmacol. 50: 333-345.

24. Harigaya, S., and A. Schwartz. 1969. Rate of calcium binding and uptake in normal animal and failing human cardiac muscle: membrane vesicles (relaxing system) and mitochondria. Circ. Res. 25: 781-794.

25. Weber, A., R. Hertz, and I. Reiss. 1966. Study of the kinetics of calcium transport by isolated fragmented sarcoplasmic reticulum. Biochem. Z. 345: 329-369.

26. Inesi, G., and S. Watanabe. 1967. Temperature dependence of ATP hydrolysis and calcium uptake by fragmented sarcoplasmic membranes. Arch. Biochem. Biophys. 121: 665-671.

27. Kaufman, R., and A. Fleckenstein. 1965. Die Bedeutung der aktionspotential-dauer und der $\mathrm{Ca}^{++}$-ionem beim zustandekommen der positiv-inotropen kaltewirkugen am warmbluter-myokard. Pflugers Archiv. Gesamte. Physiol. Menschen Tiere. 285: 1-18.

28. Langer, G. A., and A. J. Brady. 1968. The effects of temperature upon contraction and ionic exchange in rabbit ventricular myocardium. J. Gen. Physiol. 52: 682-713.

29. Whalen, W. J. 1961. The relation of work and oxygen consumption in isolated strips of cat and rat myocardium. J. Physiol.(Lond.). 157: 1-17.

30. Whalen, W. J. and J. Fangman. 1963. Respiration of heart muscle as affected by oxygen tension. Science (Wash. D. C.). 141: $274-275$.

31. Cranefield, P. F., and K. Greenspan. 1960. The rate of oxygen uptake of quiescent cardiac muscle. J. Gen. Physiol. 44: 235-249.

32. Koch-Weser, J. 1963. Effect of rate changes on strength and time course of contraction of papillary muscle. $A m$. J. Physiol. 204: 451-457.

33. Pool, P. E., B. M. Chandler, E. H. Sonnenblick, and E. Braunwald. 1968. Integrity of energy stores in cat papillary muscle. Circ. Res. 22: 213-219. 